\title{
Review Article \\ Influence on Adiposity and Atherogenic Lipaemia of Fatty Meals and Snacks in Daily Life
}

\author{
Antonio Laguna-Camacho \\ Medical Sciences Research Centre, Autonomous University of the State of Mexico, Toluca, MEX, Mexico \\ Correspondence should be addressed to Antonio Laguna-Camacho; alagunaca@uaemex.mx
}

Received 1 March 2017; Revised 2 May 2017; Accepted 9 May 2017; Published 19 June 2017

Academic Editor: Zufeng Ding

Copyright (c) 2017 Antonio Laguna-Camacho. This is an open access article distributed under the Creative Commons Attribution License, which permits unrestricted use, distribution, and reproduction in any medium, provided the original work is properly cited.

The present work reviewed the connections of changes in consumption of high-fat food with changes in adiposity and lipaemia in adults with overweight or obesity. Hyperlipaemia from higher fat meals and excessive adiposity contributes to atherogenic process. Low-fat diet interventions decrease body fat, lipaemia, and atherosclerosis markers. Inaccuracy of physical estimates of dietary fat intake remains, however, a limit to establishing causal connections. To fill this gap, tracking fat-rich eating episodes at short intervals quantifies the behavioural frequency suggested to measure (by regression of changes in real time) direct effects of this eating pattern on adiposity and atherogenic lipaemia. Such evidence will provide the basis for an approach focused on a sustained decrease in frequency of fatty meals or snacks to reduce obesity, hyperlipaemia, and atherosclerosis.

\section{Introduction}

Atherosclerosis is globally a leading cause of death [1]. Atherogenic conditions, including dyslipidaemia, are associated with excessive adiposity [2]. The high prevalence of overweight and obesity in industrialised nations posits a serious public health concern [3]. This epidemic of obesity involves widespread patterns of unhealthy eating and physical inactivity. Although this research field is highly documented (i.e., [4]), the influence of habitual eating and exercise patterns on the atherogenic process remains to be measured as it occurs.

The current work articulates research on ingestion of dietary fat as a substantial contributor to the levels of adiposity and lipaemia. First, the physiological events are integrated from high-fat food consumption at eating occasions to infiltration of circulating atherogenic lipoprotein particles into the arterial wall. Then, evidence is presented for changes in adiposity, lipaemia, and markers of atherosclerosis by means of interventions to reduce dietary fat intake. Finally, a missing step for establishing causal links is pointed out together with a proposed approach for filling this gap.

The present work considers also the behavioural field to move current research forward. The episodes of fatty meals or snacks are here addressed as a target behaviour pattern (Figure 1). The aim is to argue that episodes of high-fat intake one by one contribute to obesity, hyperlipaemia, and atherosclerosis. Therefore, a proposed implication is that individuals with overweight or obesity would benefit from consuming fewer fatty meals or snacks on a day to day basis than usual.

\section{Dietary Fat Intake and Atherogenic Process}

After an eating occasion, ingested fat is transported by lipoproteins for deposition as triglycerides within large intracellular lipid droplets in adipocytes without thermogenic cost. That is, lipids are more efficiently stored compared to carbohydrates or proteins. So a pattern of frequently consuming fatty meals or snacks would facilitate the expansion of body fatness. Accordingly, many studies have found association between high-fat diet and increased weight or body mass index $[5,6]$. A focus on adiposity was recently proposed as this tissue is primary affected by hypertrophy of adipocytes, which contributes significantly to the inflammatory state found in obesity [7]. 


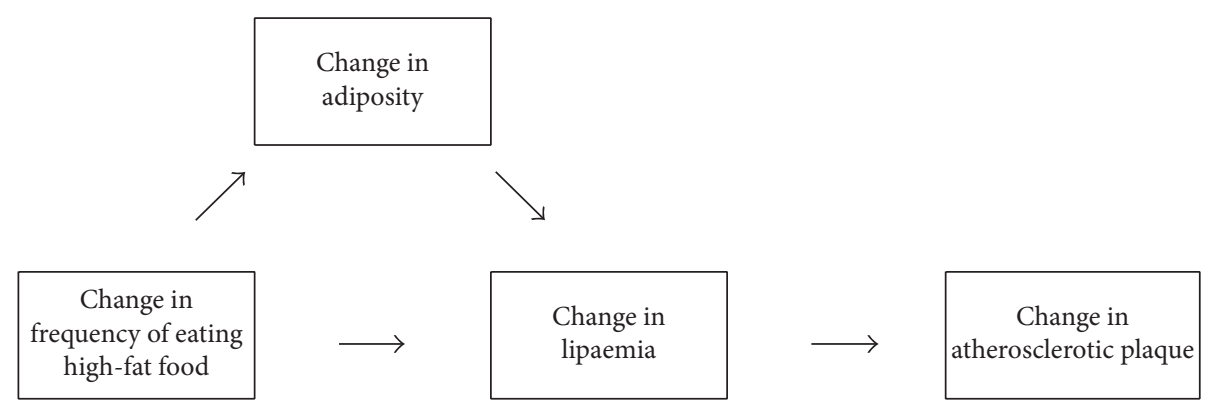

FIGURE 1: Behavioural model of influence of higher fat food consumption on adiposity and atherogenic lipaemia.

Lipolysis rate increases in response to excessive deposition of lipids in adipocytes [8-10]. Hence, hypertrophy of adipocytes contributes to higher release of free fatty acids to circulation. Also, people with overweight or obesity show an increase in plasma free fatty acids after a high-fat meal $[11,12]$. The mechanisms of such postprandial abnormalities in human beings remain unclear. However, recent research shows that every episode of excessive fat intake causes adverse systemic effects by a peak of fatty acids in plasma $[13,14]$. Thus, the more frequent a person consumes fatty foods, the more continuous also the physiological disturbances that contribute to atherosclerosis. In this case, the high flux of free fatty acids contributes directly to increase the synthesis in liver of lipoproteins that transport lipids in blood [15]. Thus, both high-fat meals and high adiposity cause hyperlipaemia in people with overweight or obesity. To provide an account of the process by which dyslipidaemia causes atherosclerosis, a biomechanical perspective is next considered.

There is an apolipoprotein B (apo B) molecule in the surface of each chylomicron (CM), very low-density lipoprotein (VLDL), intermediate-density lipoprotein (IDL), and lowdensity lipoprotein (LDL). Apo B has high molecular weight. Therefore, hyperlipaemia can elevate the blood volume or viscosity by higher number of apo B particles [16-19]. Vascular resistance compensates an increased volume of circulating blood [20]. The overstretching of the endothelium thickens the arterial wall and leads eventually to loss of compliance [21].

Endothelial failure contributes to slow blood flow as well as hematic stasis at sites of vascular resistance such as coronary arteries [22]. In state of hyperlipaemia, the blood stagnation at areas susceptible of lesion with diffuse thickening of the intima facilitates the infiltration of apo B containing lipoproteins into the arterial wall [23-25]. Lipoproteins are modified within the vascular endothelium [26]. Modified lipoproteins are a potent activator of immune cells [27]. Macrophages phagocyte modified lipoproteins in the vascular endothelium and release inflammatory cytokines such as interleukin 1 , interleukin 6 , and tumoral necrosis factor alpha (IL1, IL6, and TNF $\alpha$ ) [28-30]. Macrophages release also chemokines to attract lymphocytes Th1 and Th2 that activate $B$ cells that produce the antibodies immunoglobulin M (IgM) and $\mathrm{G}(\mathrm{IgG})$ against epitopes in the modified lipoproteins [30, 31]. Such immune response towards modified lipoproteins is a main factor of arterial inflammation $[28,32]$.

\section{Effects of Prescribing to Decrease Dietary Fat Intake}

Decreasing fat intake is a common strategy of dietetic interventions to reduce body fat and lipaemia [33-37]. Nondiabetic adults with overweight or obesity who take part in interventions based on low-fat or low-calorie diets, which usually involve strategies for decreasing dietary fat, show on average a reduction of $10 \%$ in body weight and $20 \%$ in fat mass as well as a decrease of $10 \%$ in apo B concentration [37-42]. There is also a rapid influence on apo B levels of dietetic changes. Decrease in apo B concentration of $10 \%$ was observed with a DASH diet within four weeks [43].

Prescribing dietary strategies to cut down on fat intake also decreases levels of modified lipoproteins and related immune biomarkers. For instance, reduction in body mass index by lifestyle intervention was associated with decrease in IL-6, protein-C reactive, normal $\mathrm{T}$ cell expressed and secreted, and other related markers of immune response and inflammation [44, 45]. People who lost weight in a long-term dietetic intervention showed also decreases in IL-1, IL-6, TNF $\alpha$, and leukocytes [46].

One of the most studied modified lipoproteins has been the oxidised low-density lipoprotein (ox-LDL) [47]. Like other modified lipoproteins [48], a small fraction of the oxLDL returns from the atherosclerotic lesion to the circulation [49]. So blood levels of ox-LDL could inform about the atherogenic process [50-55]. Interventions prescribing decrease in dietary fat intake have found parallel reduction in body weight or fat mass and in ox-LDL [56-58]. This is consistent with the mechanism that lowering fat intake and adiposity contributes to slow down the development of atherosclerosis. Indeed, there is reduction in the thickness of the atherosclerotic plaque over two years of maintained weight loss through low-fat diet [59].

\section{Measurement Gap to Establish Causal Connections}

Despite the well-documented positive association of changes in fat consumption with changes in fat mass and lipaemia, there is a significant bias in the core measure of dietary fat intake, the behavioural dose. Physical estimates of energy and nutrient content of diet are so inaccurate due to underreporting of food amounts that not using them in obesity research 
is suggested $[60,61]$. Estimates are also limited by influence on intake of observing people's behaviour [62, 63]. Hence, researchers are unable to measure reliably enough in everyday life conditions if any prescribed dietary fat reduction causes the observed changes in adiposity, lipaemia, or inflammation biomarkers.

The effect of low-fat diets is taken for granted from outcome measures. However, even randomised controlled trials are not free of confounding effects from other unmeasured variables [64]. For instance, participants are liable to engage in unasked changes, which may include efforts of healthy eating, dieting, or exercising to reduce weight [65, 66]. Differences in baseline characteristics of participants can generate such behavioural responses that might account for the individual variability commonly observed in dietary interventions [67].

In any case, researchers rarely monitor the behaviour changes during dietary interventions. When change in dietary intake is monitored, it is usually at intervals of several months [68]. The effect of a decrease in dietary fat consumption could be achieved within a few weeks when such reduced rate of intake comes into balance with the lower energy expenditure from a reduced body weight $[69,70]$. The outcomes of a behaviour change as they physiologically occur are still hardly considered. Identifying this prompt effect is needed for measuring the stepwise changes in adiposity and blood lipids caused by a particular pattern of eating such as eating less fat than usual at meals or between meals [71].

\section{An Alternative Behavioural Measure to Narrow the Gap}

Evidence from social psychology shows that people are highly accurate in their perception of what they normally do [72]. This psychological capacity helps people share efficiently information about their daily activities with other people. Giving a truthful account is cognitively less demanding than confabulating an event [73]. So researchers can collect reliable accounts of activities as they occur or elicit them without intrusion within the week period after their occurrence when the accuracy of recall is above $80-90 \%$ [74-77]. Such psychosocial measures of occurrence of everyday events include eating episodes. The count of a series of consecutive occurrences of a pattern of eating divided by the time of observation (i.e., number of episodes per week) gives a measure of its frequency, another dominant behavioural feature, instead of an estimate of energy/nutrient quantity or dose. Experimental designs that monitor episodes of any particular pattern of behaviour are well established in psychological science [78-80]. Tracking the episodes of an eating pattern informs about how often it is carried out over a time interval and how much a change in that frequency from an interval to another influences body fatness and related biomarkers. In the case of dietary fat consumption, the focus is on tracking episodes when people ate high-fat food at meals or between meals to measure the rate of its occurrence, which provides in turn a behaviour measure to regress changes in frequency of eating high-fat food onto changes in body weight, adiposity, blood lipids, and related immune or inflammation biomarkers. The slope of the regression gives a measurement of the effect on each of the outcomes per each unit of change in behaviour frequency.

In a small study to decrease unhealthy eating in adults with overweight or obesity, episodes of fatty meals and snacks were daily tracked during four weeks [81]. Participants reported a mean baseline of 12 high-fat meals or snacks a week, a frequency level that decreased throughout the intervention by almost half. Such sustained change in frequency of high-fat eating episodes correlated positively with change in fat mass and with change in ox-LDL. Also, the change in body fat correlated positively with change in ox-LDL.

This preliminary evidence tightens previous research showing that episodes of fatty meals and snacks over time are causally connected with change in adiposity and lipaemia as well as development of atherosclerotic plaque. Moreover, this shows that the effect of eating fatty meals and snacks on the arterial wall occurs within a few weeks.

Pursuing this research avenue would contribute to elucidating the causal links of behaviour patterns with obesity, dyslipidaemia, and atherosclerosis. This research line requires, however, substantial development. For instance, future studies could combine the present measure of frequency of an eating pattern alongside amounts of food eaten on each occasion estimated also with novel approaches that overcome limitations in accuracy of conventional dietary evaluations (i.e., [82]). A characterised pattern of eating would still correspond to a constant intake dose.

\section{Concluding Remarks}

Broad research shows consistently a positive association of fat intake with adiposity and apo B containing lipoproteins as well as with circulating levels of immune cells, cytokines, and modified lipoproteins. However, as gaps in research remain to accurately measure fat intake, there are still no measurements of causal connection between sustained intake of either more or less dietary fat and changes in anthropometry or physiological markers. The innovative use of psychosocial measures to collect records of the timings of the fatty meals and snacks as they are carried out by individuals in their everyday life would greatly benefit research and substantiate the evidence about the impact of dietary fat consumption on body fat, blood lipids, and biomarkers of atherosclerosis.

Research is beginning to accumulate showing that a bout of high-fat ingestion rapidly initiates metabolic impairments such as acute inflammation $[13,14]$. Therefore, it is reasoned that frequent episodes of fat-rich food consumption contribute in real time to the low-grade inflammatory state associated with obesity that leads to cardiovascular complications.

Reducing the habitual number of episodes of unhealthy eating may contribute to minimising the physiological disturbances found in people with overweight or obesity. So monitoring fatty meals or snacks provides an approach based on behaviour frequency that readily generates evidence to inform objective recommendations against unhealthy eating. For instance, similar to the recommendation of exercising more than three times per week [83], a recommendation 
could be formulated of consuming higher fat food no more than six times a week, which is about half the frequency found in people with unhealthy body mass index [81].

\section{Conflicts of Interest}

The author declares that there are no conflicts of interest regarding the publication of this paper.

\section{References}

[1] C. D. Mathers and D. Loncar, "Projections of global mortality and burden of disease from 2002 to 2030," PLoS Medicine, vol. 3, p. e442, 2006.

[2] P. T. James, “Obesity: the worldwide epidemic," Clinics in Dermatology, vol. 22, no. 4, pp. 276-280, 2004.

[3] P. Kopelman, "Health risks associated with overweight and obesity," Obesity Reviews, vol. 8, no. 1, pp. 13-17, 2007.

[4] S. B. Heymsfield and T. A. Wadden, "Mechanisms, pathophysiology and management of obesity," The New England Journal of Medicine, vol. 376, pp. 254-266, 2017.

[5] W. C. Willett, "Dietary fat plays a major role in obesity: No," Obesity Reviews, vol. 3, no. 2, pp. 59-68, 2002.

[6] G. A. Bray and B. M. Popkin, "Dietary fat intake does affect obesity!," American Journal of Clinical Nutrition, vol. 68, pp. 1157-1173, 1998.

[7] J. I. Mechanick, D. L. Hurley, and W. T. Garvey, "Adipositybased chronic disease as a new diagnostic term: american association of clinical endocrinologists and the american college of endocrinology position statement," Endocr Pract, vol. 23, pp. 372-378, 2017.

[8] E. Lambert and E. J. Parks, "Postprandial metabolism of meal triglyceride in humans," Biochim et Biophys Acta, vol. 1821, pp. 721-726, 2012.

[9] H. E. Bays, P. P. Toth, P. M. Kris-Etherton et al., "Obesity, adiposity, and dyslipidemia: a consensus statement from the National Lipid Association," Journal of Clinical Lipidology, vol. 7, no. 4, pp. 304-383, 2013.

[10] D. Langin, "In and out: Adipose tissue lipid turnover in obesity and dyslipidemia," Cell Metabolism, vol. 14, no. 5, pp. 569-570, 2011.

[11] K. G. Jackson, S. Lockyer, A. L. Carvalho-Wells, C. M. Williams, A. M. Minihane, and Lovegrove, "Dietary fat manipulation has a greater impact on lipid metabolism than the apolipoprotein E (epsilon) genotype-insights from the SAT gene study," Molecular Nutrition and Food Research, vol. 56, pp. 1761-1770, 2012.

[12] C. S. Katsanos, "Clinical considerations and mechanistic determinants of postprandial lipemia in older adults," Advances in Nutrition, vol. 5, no. 3, pp. 226-234, 2014.

[13] M. Herieka and C. Erridge, "High-fat meal induced postprandial inflammation," Molecular Nutrition and Food Research, vol. 58, pp. 136-146, 2014.

[14] E. Alvarez-Hernande, S. Kahl, A. Seelig, P. Begovatz, M. Irmler et al., "Acute dietary fat intake initiates alterations in energy metabolism and insulin resistance," Journal of Clinical Investigation, vol. 127, pp. 295-708, 2017.

[15] H. Duez, B. Lamarche, R. Valero et al., "Both intestinal and hepatic lipoprotein production are stimulated by an acute elevation of plasma free fatty acids in humans," Circulation, vol. 117, pp. 2369-2376, 2008.
[16] A. H. Seplowitz, S. Chien, and F. R. Smith, "Effects of lipoproteins on plasma viscosity," Atherosclerosis, vol. 38, pp. 89-95, 1981.

[17] S. B. Solerte, M. Fioravanti, A. L. Patti et al., "Increased plasma apolipoprotein levels and blood hyperviscosity in non-insulindependent diabetic patients: role of the occurrence of arterial hypertension," Acta Diabetologica Latina, vol. 24, pp. 341-349, 1987.

[18] W. Koenig, M. Sund, E. Ernst, W. Mraz, V. Hombach, and U. Keil, "Association between rheology and components of lipoproteins in human blood: results from the MONICA project," Circulation, vol. 85, pp. 2197-2204, 1992.

[19] A. Slyper, A. Le, J. Jurva, and D. Gutterman, "The influence of lipoproteins on whole-blood viscosity at multiple shear rates," Metabolism, vol. 54, pp. 764-768, 2005.

[20] R. B. Devereux, D. B. Case, M. H. Alderman, T. G. Pickerung, S. Chien, and J. H. Laragh, "Possible role of increased blood viscosity in the hemodynamics of systemic hypertension," American Journal of Cardiology, vol. 85, pp. 1265-1267, 2000.

[21] K. R. Kensey, "The mechanistic relationships between hemorheological characteristics and cardiovascular disease," Current Medical Research and Opinion, vol. 19, no. 7, pp. 587-596, 2003.

[22] J. M. Jung, A study on rheological properties of blood and improvements with high-voltage plasma discharge [Ph.D. thesis], Drexel University, 2012.

[23] J. H. Rapp, A. Lespine, R. L. Hamilton et al., "Triglyceride-rich lipoproteins isolated by selected-affinity anti-apolipoprotein B immunosorption from human atherosclerotic plaque," Arteriosclerosis and Thrombosis, vol. 14, pp. 1767-1774, 1994.

[24] K. J. Williams and I. Tabas, "The response-to-retention hypothesis of early atherogenesis," Arterioscler Thromb Vasc Biol, vol. 15, pp. 551-561, 1995.

[25] S. D. Proctor and J. C. Mamo, "Retention of fluorescent-labelled chylomicron remnants within the intima of the arterial-wall evidence that plaque cholesterol may be derived from postprandial lipoproteins," European Journal of Clinical Investigation, vol. 28, pp. 497-503, 1998.

[26] T. Hevonoja, M. O. Pentikainen, M. T. Hyvonen, P. T. Kovanen, and M. Ala-Corpela, "Structure of low density lipoproteoin particles: basis for undestanding molecular changes in modified LDL," Biochimica et Biophysica Acta, vol. 1488, pp. 189-210, 2000.

[27] M. J. Hubler and A. J. Kennedy, "Role of lipids in the metabolism and activation of immune cells," The Journal of Nutritional Biochemistry, vol. 34, pp. 1-7, 2016.

[28] G. K. Hansson and P. Libby, "The immune response in atherosclerosis: a double-edged sword," Nature Reviews Immunology, vol. 6, pp. 508-519, 2006.

[29] S. Samson, L. Mundkur, and V. Vakkar, "Immune response to lipoproteins in atherosclerosis," Cholesterol, Article ID 571846, 2012.

[30] A. K. L. Robertson and G. K. Hansson, "T cells in atherogenesis: for better or for worse?" Arteriosclerosis, Thrombosis, and Vascular Biology, vol. 26, pp. 2421-2432, 2006.

[31] J. Frostegard, A. K. Ulfgren, P. Nyberg et al., "Cytokine expression in advanced human atherosclerotic plaques: dominance of pro-inflammatory (Th1) and macrophage-stimulating cytokines," Atherosclerosis, vol. 145, pp. 33-43, 1999.

[32] G. K. Hansson and A. Hermansson, "The immune system in atherosclerosis," Nature Immunology, vol. 12, pp. 204-212, 2011. 
[33] D. C. Chan, G. F. Watts, T. W. K. Ng, S. Yamashita, and P. H. Barret, "Effect of weight loss on markers of triglyceride-rich lipoprotein metabolism in the metabolic syndrome," European Journal of Clinical Investigation, vol. 38, pp. 743-751, 2008.

[34] Y. Cao, D. T. Mauger, C. L. Pelkman, G. Zhao, S. M. Townsend, and P. M. Kris-Etherton, "Effects of moderate (MF) versus lower fat (LF) diets on lipids and lipoproteins: a meta-analysis of clinical trials in subjects with and without diabetes," Journal of Clinical Lipidology, vol. 3, no. 1, pp. 19-32, 2009.

[35] S. U. Dombrowski, A. Avenell, and F. F. Sniehott, "Behavioural interventions for obese adults with additional risk factors for morbidity: systematic review of effects on behaviour, weight and disease risk factors," Obesity Facts, vol. 3, pp. 377-396, 2010.

[36] L. Hooper, A. Abdelhamid, H. J. Moore, W. Douthwaite, C. M. Skeaff, and C. D. Summerbell, "Effect of reducing total fat intake on body weight: Systematic review and meta-analysis of randomised controlled trials and cohort studies," BMJ (Online), vol. 345, no. 7891, Article ID e7666, 2013.

[37] A. L. Borel, J. A. Nazare, J. Smith et al., "Visceral and not subcutaneous abdominal adiposity reduction drives the benefits of 1-year lifestyle modification program," Obesity, vol. 20, pp. 12231233, 2012.

[38] P. W. Siri-Tarino, P. T. Williams, H. S. Fernstrom, R. S. Rawlings, and R. M. Krauss, "Reversal of small, dense LDL subclass phenotype by normalization of adiposity," Obesity, vol. 17, pp. 1768-1775, 2009.

[39] R. M. Krauss, P. J. Blanche, R. S. Rawlings, H. S. Fernstrom, and P. T. Williams, "Separate effects of reduced carbohydrate intake and weight loss on atherogenic dyslipidemia," The American Journal of Clinical Nutrition, vol. 83, pp. 1025-1031, 2006.

[40] G. D. Brinkworth, M. Noakes, J. D. Bucley, J. B. Keogh, and P. M. Clifton, "Long-term effects of a very-low-carbohydrate weight loss diet compared with an isocaloric low-fat diet after $12 \mathrm{mo,"}$ The American Journal of Clinical Nutrition, vol. 90, pp. 23-32, 2009.

[41] D. C. Chan, G. F. Watts, S. K. Gan, E. M. M. Ooi, and P. H. R. Barrett, "Effect of ezetimibe on hepatic fat, inflammatory markers, and apolipoprotein B-100 kinetics in insulin-resistant obese subjects on a weight loss diet," Diabetes Care, vol. 33, pp. 1134-1139, 2010.

[42] E. Pelletier-Beaumont, B. J. Arsenault, N. Almeras et al., "Normalization of visceral adiposity is required to normalize apolipoprotein B levels in response to a healthy eating/physical activity lifestyle modification program in viscerally obese men," Atherosclerosis, vol. 221, pp. 577-582, 2012.

[43] L. Hodson, K. E. Harnden, R. Roberts, A. L. Dennis, and K. N. Frayn, "Does the DASH diet lower blood pressure by altering peripheral vascular function?" Journal of Human Hypertension, vol. 24, pp. 312-319, 2010.

[44] C. Herder, M. Peltonen, W. Koenig et al., "Systemic immune mediators and lifestyle changes in the prevention of type 2 diabetes: Results from the Finnish Diabetes Prevention Study," Diabetes, vol. 55, no. 8, pp. 2340-2346, 2006.

[45] C. Herder, M. Peltonen, W. Koenig et al., "Anti-inflammatory effect of lifestyle changes in the Finnish Diabetes Prevention Study," Diabetologia, vol. 52, no. 3, pp. 433-442, 2009.

[46] J. S. Chae, J. K. Paik, R. Kang et al., "Mild weight loss reduces inflammatory cytokines, leucocyte count and oxidative stress in overweight and moderately obese participants treated for 3 years with dietary modification," Nutrition Research, vol. 33, pp. 195-203, 2013.
[47] R. Carmena, P. Duriez, and J. C. Fruchart, "Atherogenic lipoprotein particles in atherosclerosis," Circulation, vol. 109, pp. III2III7, 2004.

[48] K. Nakajíma, T. Nakano, and A. Tanaka, "The oxidative modification hypothesis of atherosclerosis: the comparison of atherogenic effects on oxidized LDL and remnant lipoproteins in plasma," Clinica Chimica Acta, vol. 367, pp. 36-47, 2006.

[49] H. N. Hodis, D. M. Kramsch, and P. Avogaro, "Biochemical and cytotoxic Characteristics of an in vivo circulating oxidized low density lipoprotein," Journal of Lipid Research, vol. 35, pp. 669677, 1994.

[50] P. Moriel, F. S. Okawabata, and D. S. P. Abdalla, "Oxidized lipoproteins in blood plasma: possible marker of atherosclerosis progression," Life, vol. 48, pp. 413-417, 1999.

[51] J. Hulthe and B. Fagerberg, "Circulating oxidized LDL is associated with subclinical atherosclerosis development and inflammatory cytokines (AIR Study)," Arteriosclerosis, Thrombosis and Vascular Biology, vol. 22, pp. 1162-1167, 2002.

[52] K. Wallenfeldt, B. Fagerberg, J. Wikstrand, and J. Hulthe, "Oxidized low-density lipoprotein in plasma is a prognostic marker of subclinical atherosclerosis development in clinically healthy men," Journal of Internal Medicine, vol. 256, pp. 413-420, 2004.

[53] M. Granér, T. Nakano, S. J. Sarna, M. S. Niemiene, M. Syvanne, and M. R. Taskinen, "Impact of postprandial lipaemia on lowdensity lipoprotein (LDL) size and oxidized LDL in patients with coronary artery disease," European Journal of Clinical Investigation, vol. 36, pp. 764-770, 2006.

[54] T. Weinbrenner, H. Schroder, V. Escurriol, M. Fito, R. Elosua et al., "Circulating oxidized LDL is associated with increased waist circumference independent of body mass index in men and women," American Journal of Clinical Nutrition, vol. 83, pp. 3035, 2006.

[55] A. Taleb, J. L. Witztum, and S. Tsimikas, "Oxidized phospholipids on apoB-100-containing lipoproteins: a biomarker predicting cardiovascular disease and cardiovascular events," Biomarkers in Medicine, vol. 5, pp. 673-694, 2011.

[56] T. Vasankari, M. Fogelholm, K. Kukkonen-Harjula et al., "Reduced oxidized low-density lipoprotein after weight reduction in obese premenopausal women," International Journal of Obesity, vol. 25, pp. 205-211, 2001.

[57] A. Lapointe, J. Goulet, C. Couillard, B. Lamarche, and S. Lemieux, "A nutritional intervention promoting the mediterranean food pattern is associated with decrease in circulating oxidized LDL particles in healthy women from the Québec city metropolitan area," Journal of Nutrition, vol. 135, pp. 410-415, 2005.

[58] E. Tumova, W. Sun, P. H. Jones, M. Vrablik, C. M. Ballantyne, and R. C. Hoogeveen, "The impact of rapid weight loss on oxidative stress markers and the expression of the metabolic syndrome in obese individuals," Journal of Obesity, Article ID 729515, 2013.

[59] I. Shai, J. D. Spence, D. Schwarzfuchs et al., "Dietary intervention to reverse carotid atherosclerosis," Circulation, vol. 121, no. 10, pp. 1200-1208, 2010.

[60] N. V. Dhurandhar, D. Schoeller, A. W. Brown et al., "Energy balance measurement: when something is not better than nothing," International Journal of Obesity, vol. 39, pp. 1109-1113, 2015.

[61] A. F. Subar, L. S. Freedman, J. A. Tooze et al., "Addressing current criticism regarding the value of self-report dietary data," Journal of Nutrition, vol. 145, no. 12, pp. 2639-2645, 2015. 
[62] D. A. Booth and A. Laguna-Camacho, "Physical versus psychosocial measures of influences on human obesity. Comment on Dhurandhar et al.", International Journal of Obesity, vol. 39, no. 7, pp. 1177-1178, 2015.

[63] D. P. French and S. Sutton, "Reactivity of measurement in health psychology: how much of a problem is it? What can be done about it?" British Journal of Health Psychology, vol. 15, pp. 453468, 2010.

[64] V. W. Berger and S. Weinstein, "Ensuring the comparability of comparison groups: Is randomization enough?" Controlled Clinical Trials, vol. 25, no. 5, pp. 515-524, 2004.

[65] R. A. Carels, J. Harper, and K. Konrad, "Qualitative perceptions and caloric estimations of healthy and unhealthy foods by behavioral weight loss participants," Appetite, vol. 46, no. 2, pp. 199-206, 2006.

[66] D. Larkina and C. R. Martin, "Caloric estimation of healthy and unhealthy foods in normal-weight, overweight and obese participants," Eating Behaviors, vol. 23, pp. 91-96, 2016.

[67] M. R. de Boer, W. E. Waterlander, L. D. J. Kuijper, I. H. M. Steenhuis, and J. W. R. Twisk, “Testing for baseline differences in randomized controlled trials: an unhealthy research behavior that is hard to eradicate," International Journal of Behavioral Nutrition and Physical Activity, vol. 12, no. 4, 2015.

[68] T. Mann, A. J. Tomiyama, E. Westling, A. M. Lew, B. Samuels, and J. Chatman, "Medicare's search for effective obesity treatments: diets are not the answer," American Psychologist, vol. 62, pp. 220-233, 2007.

[69] J. S. Garrow, Energy Balance and Obesity in Man, Elsevier North Holland Pub, Amsterdam, The Netherlands, 1978.

[70] O. G. Edholm, J. M. Adam, M. J. R. Healy, H. S. Wolff, R. Goldsmith, and T. W. Best, "Food intake and energy expenditure of army recruits," British Journal of Nutrition, vol. 24, no. 4, pp. 1091-1107, 1970.

[71] A. Laguna-Camacho, Patterns of eating and exercise that reduce weight [Ph.D. thesis], University of Birmingham, 2013.

[72] L. Jussim, "Précis of social perception and social reality: why accuracy dominates bias and self-fulfilling prophecy," Behavioral and Brain Sciences, vol. 16, pp. 1-66, 2015.

[73] A. Vrij, P. A. Granhag, S. Mann, and S. Leal, "Outsmarting the liars: toward a cognitive lie detection approach," Current Directions in Psychological Science, vol. 20, no. 1, pp. 28-32, 2011.

[74] J. J. Skowronski, A. L. Betz, C. P. Thompson, and L. Shannon, "Social Memory in Everyday Life: Recall of Self-Events and Other-Events," Journal of Personality and Social Psychology, vol. 60, no. 6, pp. 831-843, 1991.

[75] A. M. Armstrong, A. MacDonald, I. W. Booth, R. G. Platts, R. C. Knibb, and D. A. Booth, "Errors in memory for dietary intake and their reduction," Applied Cognitive Psychology, vol. 14, pp. 183-191, 2000.

[76] G. Kristo, S. M. J. Janssen, and J. M. J. Murre, "Retention of autobiographical memories: an internet-based diary study," Memory, vol. 17, no. 8, pp. 816-829, 2009.

[77] M. A. Conway, "Episodic memories," Neuropsychologia, vol. 47, no. 11, pp. 2305-2313, 2009.

[78] P. Sedlmeier and T. Betsch, Etc. Frequency Processing and Cognition, University Press, Oxford, UK, 2002.

[79] D. H. Barlow, M. K. Nock, and M. Hersen, Single Case Experimental Designs: Strategies for Studying Behaviour Change, Pearson education, Boston, USA, 3rd edition, 2009.

[80] R. L. Tate, M. Perdices, U. Rosenkoetter, S. McDonald, L. Togher, S. Shadish et al., "The single-case reporting guideline in behavioural interventions (SCRIBE) 2016: explanation and elaboration," Archives of Scientific Psychology, vol. 4, no. 1, pp. 10-31, 2016.

[81] A. Laguna-Camacho, A. S. Alonso-Barreto, and H. MendietaZerón, "Direct effect of fatty meals and adiposity on oxidised low-density lipoprotein," Obes Res Clin Pract, vol. 9, pp. 298300, 2015.

[82] F. J. Pendergast, N. D. Ridgers, A. Worsley, and S. McNaughton, "Evaluation of a smartphone food diary application using objectively measured energy expenditure," International Journal of Behavioral Nutrition and Physical Activity, vol. 14, no. 30, 2017.

[83] Department of Health and Human Services, Physical Activity Guidelines for Americans, DHHS, Washington, USA, 2008. 

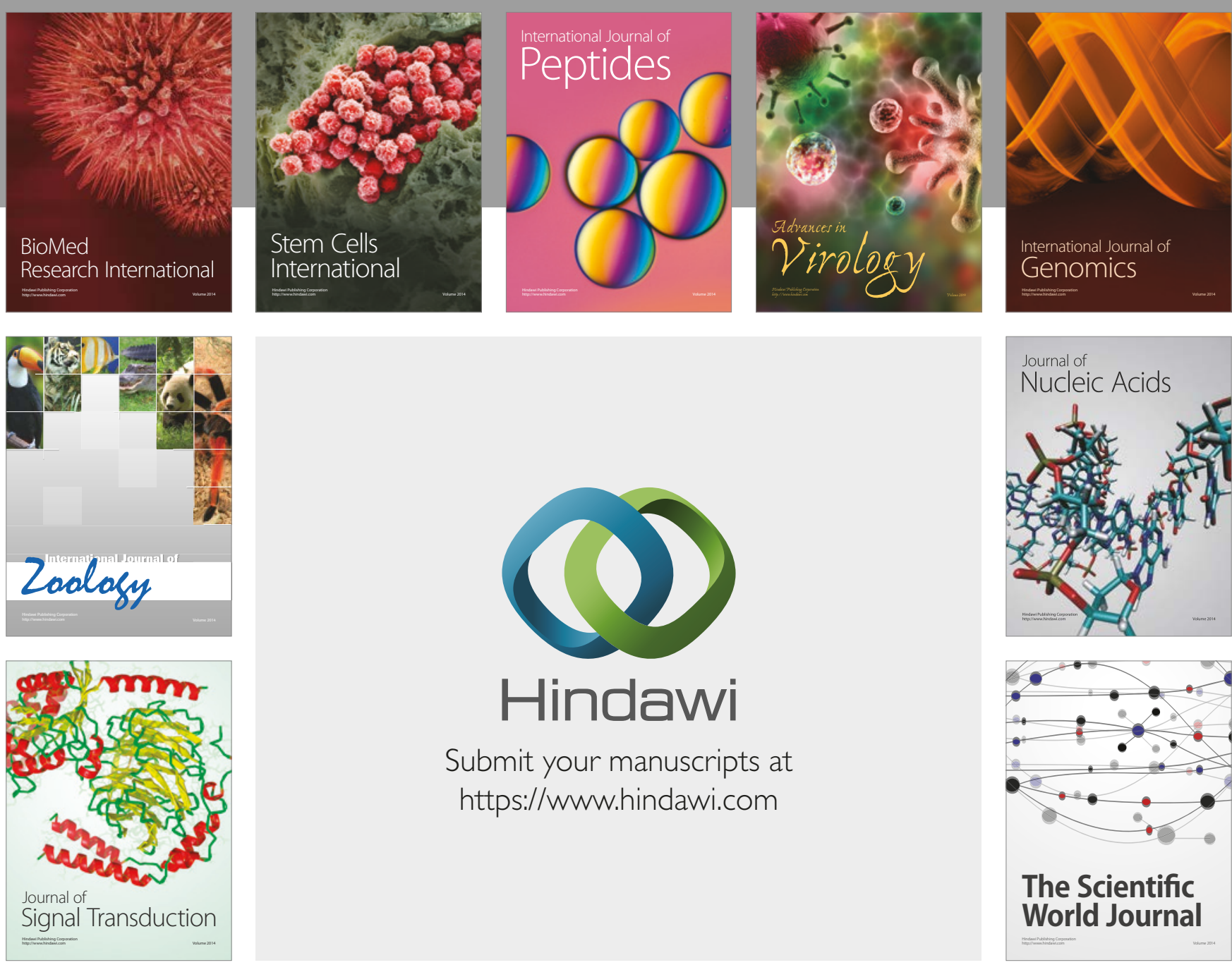

Submit your manuscripts at

https://www.hindawi.com
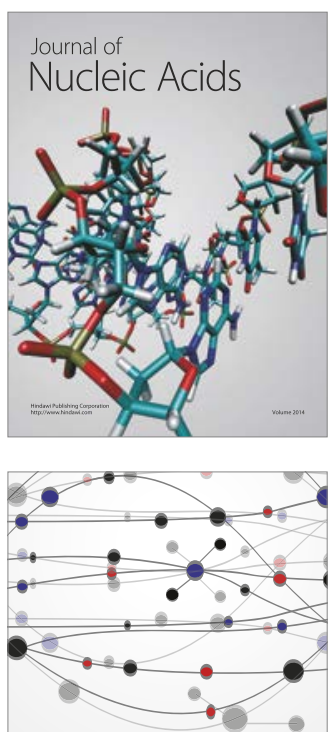

The Scientific World Journal

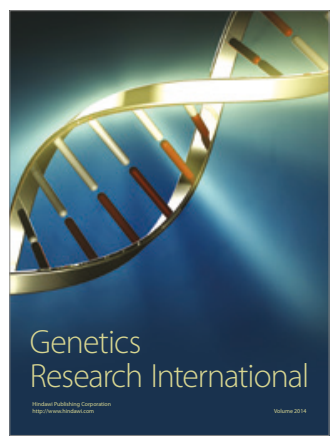

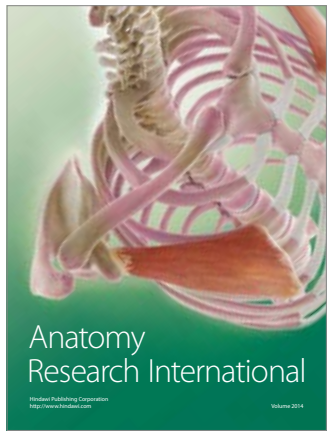

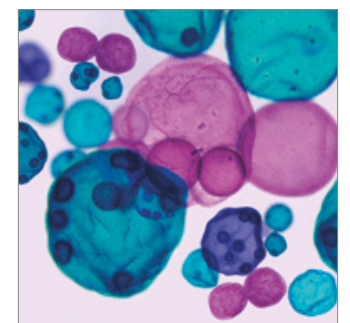

International Journal of Microbiology
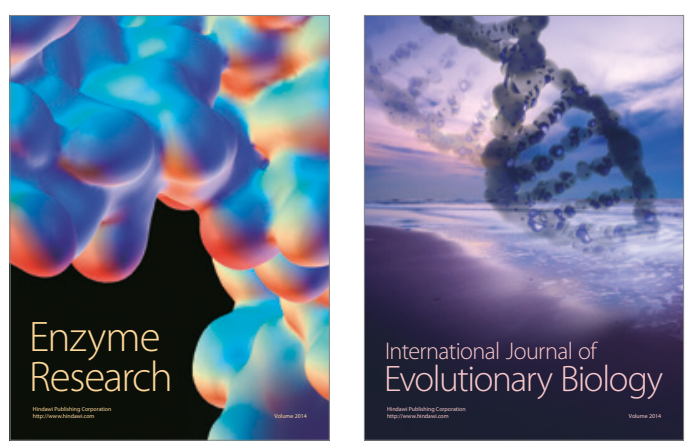
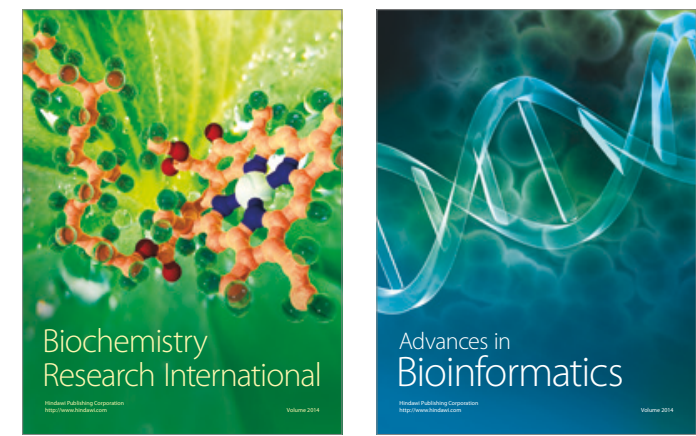

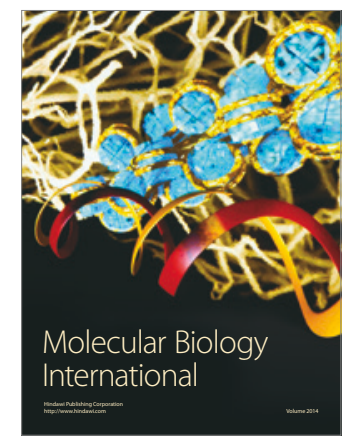

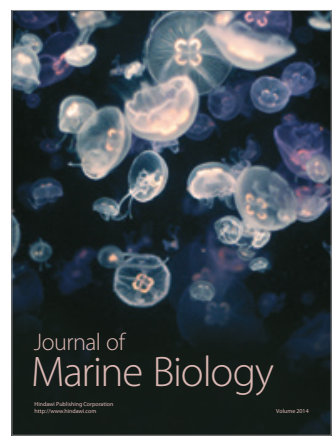

